DOI: 10.20472/IAC.2018.038.033

UMER RAMZAN

University of Lahore, Pakistan

\title{
INVESTIGATING THE ROLE OF CONTENT BASED SOCIAL MEDIA MARKETING IN BUILDING CUSTOMER LOYALTY AND MOTIVATING USERS TO FORWARD CONTENT
}

\begin{abstract}
:
The effectiveness of content on social media allows businesses to establish lasting relationships with their audience. It highlights the competence of a business and allows a firm to gain the trust of their audience by providing them the content they value. Well designed content also enables a website or social media presence to attract traffic and improve its google search ranking. It also motivates a user to share content with others. The concept of content-based social media marketing is very important and taking much concentration due to increasing trend of using social media and what drives customers to share the content and what kind of trust lead them to do so. A carefully planned content marketing strategy may help a company to get positive responses from consumers and maintain strong relationships with them by gaining their trust in terms of providing them a solution to what they are looking for. The study has investigated that how the right content of social media can increase customer loyalty and motivation to forward content through customer engagement and customer trust. Is there any impact of content on all these variables or not. For measuring the impact of content on social media marketing, this study collected data from people who use social media platforms and 200 respondents were selected with a questionnaire of 49 questions. The research includes that there is a positive impact of content-based social media marketing on increasing customer loyalty and motivation to forward content along with the mediating mechanisms of customer engagement and trust. Trust enables customers to share the content due to a high level of engagement.
\end{abstract}

\section{Keywords:}

Content Marketing, Social Media Marketing, Customer Trust, Customer Engagement, Customer Loyalty 